\title{
Hyphenation of gas chromatographic techniques with isotope ratio mass spectrometry: Present status and future
}

\author{
C.B. Douthitt \\ Finnigan MAT, 9412 Rocky Branch Dr., Dallas, TX 75243, USA
}

\begin{abstract}
Isotope ratio mass spectrometers (IRMS) are highly specialized sector field mass spectrometers which are dedicated to a single purpose: high precision and high accuracy measurements of the variations in natural isotopic abundance of the light stable isotopes of $\mathrm{C}, \mathrm{O}, \mathrm{H}$, $\mathrm{N}, \mathrm{S}$, (and much less frequently, $\mathrm{Cl}, \mathrm{Si}$, and $\mathrm{Se}$ ). These mass spectrometers have a fixed array of Faraday collectors and they are built to analyze a very small range of simple molecular species (CO2, N2, H2, SO2, $\mathrm{CO}$ ). The main applications were in the characterization and mass balance of the various geological cycles which couple the hydrosphere, the lithosphere, and the atmosphere. Systematic applications of stable isotope methodology to the biosphere had to await the coupling of gas chromatography (GC) with IRMS, which allowed the exquisite chemical resolving power of the GC to be hyphenated with the extraordinary precision of the IRMS.
\end{abstract}

Since the commercial introduction in 1988 of direct online coupling between capillary and packed column gas chromatography (GC) and isotope ratio mass spectrometry (IRMS), the hyphenation of GC and IRMS techniques evolved from three quite different starting points and developed along parallel but separate lines (Fig. 1): analysis of ${ }^{13} \mathrm{C}$ of $\mathrm{CO}_{2}$ in breath; analysis of chromatographically resolved organic compounds for ${ }^{13} \mathrm{C},{ }^{15} \mathrm{~N},{ }^{18} \mathrm{O}$ and $\mathrm{D}$; and analysis of bulk materials for ${ }^{13} \mathrm{C},{ }^{15} \mathrm{~N},{ }^{34} \mathrm{~S},{ }^{18} \mathrm{O}$, and $\mathrm{D}$. In order to understand the currently used terminology, it is useful to briefly review these several lines of descent. One group, largely organic geochemists, was interested in using ${ }^{13} \mathrm{C} /{ }^{12} \mathrm{C}$ to characterize natural biomarkers in petroleum (Fig. 2a) and compounds in natural gas, to help understand the generation and migration of hydrocarbons. Because these researchers were quite familiar with capillary gas chromatography, the nomenclature that they introduced was used to communicate the methodology to GC and GCMS researchers, and so "isotope ratio monitoring-GCMS" (IRM-GCMS) was coined to contrast it with "selected ion monitoring" or "multiple ion monitoring" techniques. The general application has become known as "compound specific isotope analysis" (CSIA). CSIA was relatively quickly extended to allow measurement of ${ }^{15} \mathrm{~N} /{ }^{14} \mathrm{~N}$ on $\mathrm{N}$-bearing molecules such as derivatized amino acids (Fig. 2b).

Another group, comprising largely oceanographers and agronomists, was mainly interested in using ${ }^{15} \mathrm{~N} /{ }^{14} \mathrm{~N}$ to trace nitrogen cycling in both natural and experimentally labeled situations. Because this group was largely interested in analysis of bulk solid materials rather than of specific com- pounds, it was the commercially available Carlo Erba NA series elemental which became the workhorse for sample preparation and introduction. These systems, while seemingly unrelated to GCs, use a GC column to separate the combustion products, and thus represent a variation on the theme of GC-IRMS. Because the point of reference for these workers was the standard "dual inlet system" in which pure $\mathrm{N}_{2}$ (or $\mathrm{CO}_{2}$ ) was inlet into the mass spectrometer from a reservoir, the new technique, which used in contrast a $\mathrm{He}$ carrier gas, became known as "continuous flow" IRMS or "CF-IRMS". The general application is sometimes referred to as "bulk stable isotope analysis" or BSIA. BSIA was rapidly extended to ${ }^{13} \mathrm{C} /{ }^{12} \mathrm{C}$, and somewhat later to ${ }^{34} \mathrm{~S} /{ }^{\beta 2} \mathrm{~S}$.

A third group, drawn largely from medical researchers, pursued measuring the ${ }^{13} \mathrm{C}$ of $\mathrm{CO}_{2}$ in breath as a probe of metabolic activity using artificially labeled (enriched) ${ }^{13} \mathrm{C}$ substrates. This was most easily accomplished by a combination of headspace sampling and loop injection onto a GC column capable of resolving $\mathrm{CO}_{2}$ from other components of breath. This application is widely known as " ${ }^{13} \mathrm{C}$ breath test" $\left({ }^{13} \mathbf{C}-\mathbf{B T}\right)$ and the technique as GC-IRMS. The most widely used test is the "13 C-Urea Breath Test" for the confirmation of the presence of the ulcerative bacterium, Helicobacter pylori.

The features common to all three applications include the use of a GC, and thus a carrier gas, to effect chromatographic separation of the compound or molecule of interest and so, to the IRMS researcher, all three applications can be classified as CF-IRMS techniques. In the CSIA technique, the chromatography is done prior to sample decomposition (via combustion); in BSIA, the chromatography is done post-combustion. In the ${ }^{13} \mathbf{C}-\mathbf{B T}$, it is the body that the does the combustion, and the $\mathrm{GC}$ is used to resolve the analyte $\left(\mathrm{CO}_{2}\right)$ from the other components of the respired air. These

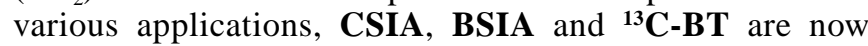
merged in modern commercially available instruments.

It is only quite recently that CSIA and BSIA have been extended from ${ }^{13} \mathrm{C}$ and ${ }^{15} \mathrm{~N}$ analyses to allow measurement of ${ }^{18} \mathrm{O} /{ }^{16} \mathrm{O}$ (Fig. 2c, 1996) and $\mathrm{D} / \mathrm{H}$ (Fig. 2d, 1998) of Oand H-bearing organic molecules and mixtures. Decomposition of the samples to the mass spectrometer analyte gases, $\mathrm{CO}$ and $\mathrm{H}_{2}$, is accomplished via "quantitative catalytically-aided thermochemolysis", referred to in acronyms as TC. The ability to measure the $\mathrm{D} / \mathrm{H}$ ratio of nanomolar quantities of $\mathrm{H}_{2}$ in a He carrier is complicated by tailing of 


\section{ISOTOPE RATIOS BY MASS SPECTROMETRY}

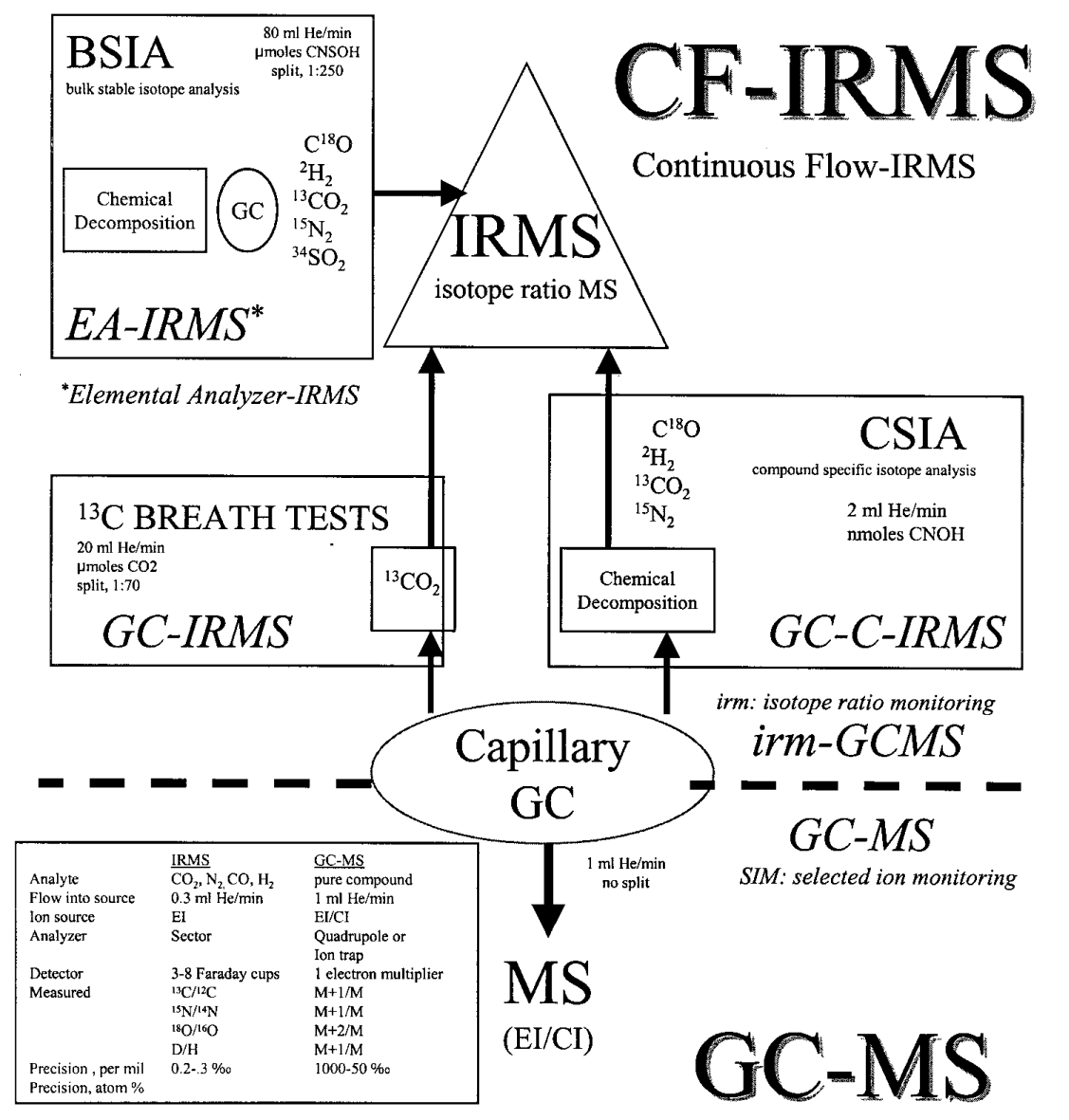

Figure 1. The principal subdivisions of and figures of merit for "continuous flow-isotope ratio mass spectrometry" (CF-IRMS), contrasted with GC-MS techniques in use for measurement of isotope ratios. the large ${ }^{4} \mathrm{He}$ peak, and its solution has required modification to the standard IRMS (larger dispersion) and the collector array (a retardation lens built into the $m / z=3$ Faraday cup). These breakthroughs, the TC decomposition which allows simple and quantitative conversion of biological $\mathrm{O}$ and $\mathrm{H}$ into $\mathrm{CO}$ and $\mathrm{H}_{2}$, and the mass spectrometer innovations which allow accurate and precise isotopic measurements to be made on $\mathrm{CO}$ and $\mathrm{H}_{2}$ are, without doubt, the two most important advances in the last decade of IRMS. It is now possible to analyze both bulk tissues as well as individual amino acids, fatty acids, and carbohydrates not just for the ${ }^{13} \mathrm{C}$ signature but also for $\mathrm{D},{ }^{18} \mathrm{O}$, and ${ }^{15} \mathrm{~N}$. These analyses can be done at either enriched levels, in which "stable label" tracers are introduced and followed, or at natural levels, allowing the use of subtle natural tracers, such as introducing a $\mathrm{C}_{4}$ component into a $\mathrm{C}_{3}$ diet. The analysis of bulk tissues allows access to the fine scale isotopic record recorded in hair, finger and toenails which, faithfully and with high resolution, record variations in the isotopic composition of metabolic pools from which they form.
Work is currently in progress on completely parallel implementation of both a IRMS and an ion trap or quadrupole mass spectrometer, so that individual peaks can be isotopically characterized while simultaneously being identified in a scanning mass spectrometer. While progress on LCIRMS for isotopic analysis on biomolecules without derivatization was initially rapid, there is no near term outlook for a commercially viable implementation of the technique. Novel integrations of gas chromatography and pyrolytic sample decomposition followed by IRMS have allowed measurements to be made of ${ }^{13} \mathrm{C}$ concentrations of specific sites, position specific isotopic analysis (PSIA). These exciting new techniques are being rapidly adopted in the petroleum, environmental, flavor/fragrance, and medical fields, and are allowing IRMS to assume its proper position in the analytical arsenal, alongside other tools which yield isotopic information (quadrupole MS, NMR). It can be expected that the hyphenated technique of GC-IRMS will become a standard fixture in the modern chemical laboratory. 


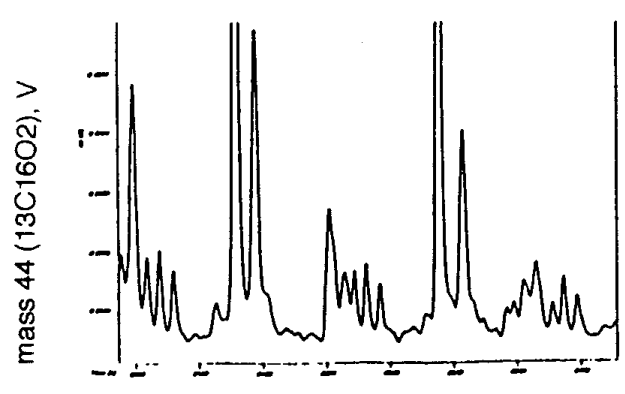

a. n-alkane fraction of petroleum

$$
\begin{array}{ll}
\text { analyte: } & \mathrm{CO}_{2} \\
\text { on-column: } & 10 \mathrm{ng} \\
\text { reproducibility: } & 0.02 \% \\
\text { introduced: } & 1988
\end{array}
$$

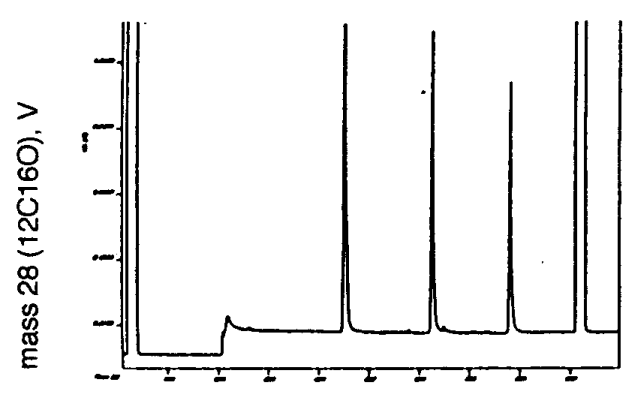

c. flavor extract

analyte: $\quad \mathrm{CO}$ on-column: $400 \mathrm{ng}$ reproducibility: $0.06 \%$ introduced: 1996

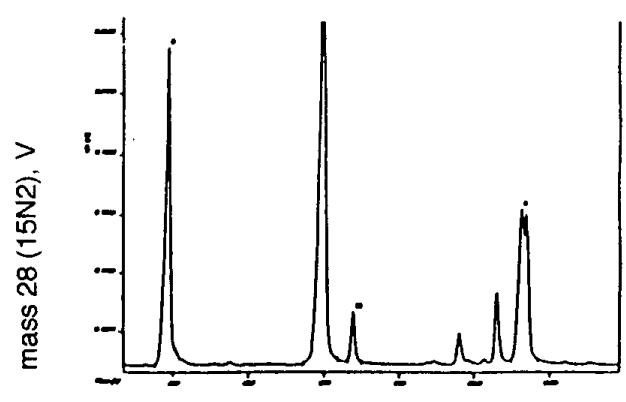

b. amino acids, derivatized

$\begin{array}{ll}\text { analyte: } & \mathrm{N}_{2} \\ \text { on-column: } & 200 \mathrm{ng} \\ \text { reproducibility: } & 0.05 \% \\ \text { introduced: } & 1992\end{array}$

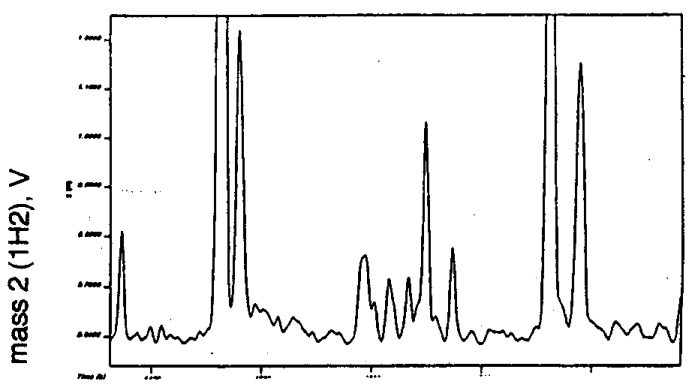

d. n-alkane fraction of petroleum

analyte: $\quad \mathrm{H}_{2}$ on-column: $200 \mathrm{ng}$ reproducibility: $0.30 \%$ introduced: 1998

\section{Typical IRM-GCMS Spectra (intensity of major ion beam vs. time)}

Figure 2. Typical isotope ratio monitoring-GCMS (irm-GCMS) chromatograms obtained during measurement of ${ }^{13} \mathrm{C} /{ }^{12} \mathrm{C},{ }^{15} \mathrm{~N} /{ }^{14} \mathrm{~N},{ }^{18} \mathrm{O} /{ }^{16} \mathrm{O}$, and $\mathrm{D} / \mathrm{H}$ of individual GC peaks; the spectra are the signal of the major isotopomer of the analyte of interest, analogous to a "mass selective" FID trace. (a) Chromatogram of $\mathrm{m} / z=44$ of $\mathrm{CO}_{2}$ vs. time from the $n$-alkane fraction of a petroleum sample, obtained during an analysis of ${ }^{13} \mathrm{C} /{ }^{12} \mathrm{C}$; (b) Chromatogram of $m / z=28$ of $\mathrm{N}_{2}$ vs. time for derivatized amino acids obtained during an analysis of ${ }^{15} \mathrm{~N} /{ }^{14} \mathrm{~N}$; (c) chromatogram of $\mathrm{m} / \mathrm{z}=28$ of $\mathrm{CO}$ vs. time for a flavor extract obtained during an analysis of ${ }^{18} \mathrm{O} /{ }^{16} \mathrm{O}$; (d) chromatogram of $m / z=2$ of $H_{2}$ vs. time for an $n$-alkane fraction of a petroleum, obtained during an analysis of $D / H$. 